\title{
Strontium cobalt oxide misfit nanotubes
}

Leela S. Panchakarla ${ }^{* \neq \neq}+\underline{\text { Luc Lajaunie }},{ }^{+} \perp \underline{\text { Ashwin Ramasubramaniam }},{ }^{* \S} \underline{\text { Raul Arenal }},{ }^{* * \|}$ and Reshef Tenne ${ }^{\dagger}$

${ }^{\dagger}$ Department of Materials and Interfaces, Weizmann Institute of Science, 76100 Rehovot, Israel

* Laboratorio de Microscopías Avanzadas, Instituto de Nanociencia de Aragón, Universidad de Zaragoza, 50018 Zaragoza, Spain

$\S$ Department of Mechanical and Industrial Engineering, University of Massachusetts Amherst, Amherst, Massachusetts 01003, United States

" ARAID Foundation, 50018 Zaragoza, Spain

${ }^{\neq}$Present Address: Department of Chemistry, Indian Institute of Technology Bombay, Powai, Mumbai 400076, India.

\begin{abstract}
Low-dimensional misfit layered compounds have been found to have ultra-low thermal conductivity, which is attributed to their unique structure and the low-dimensionality. There are a few studies reporting the preparation of sulfide-based misfit nanotubes but only one study on oxide-based analogs. In this investigation, we report a new oxide-based misfit nanotube derived from misfit layered strontium cobaltite. Thorough structural investigation by electron microscopy techniques, including electron diffraction, aberration corrected highresolution (scanning) transmission electron microscopy and electron energy-loss spectroscopy along with density functional theory calculations show that these nanotubes consist of alternating layers of $\mathrm{SrCoO}_{2}$ and $\mathrm{CoO}_{2}$. We have studied systematically the effect of base concentration on the structure and composition of the nanotubes, which reveals the importance of misfit stress to tightly roll the structure into tubular form and thus control the synthesis. Electronic structure calculations find that the structures are semiconducting with a ferrimagnetic ground state. Our studies further extend the family of bulk misfit layered oxides into the $1 \mathrm{D}$ realm with potential applications in thermoelectric and electronic devices.
\end{abstract}




\section{INTRODUCTION}

Misfit layered compounds have been a subject of interest for the last three decades due mainly to their unique structure that lends them to potential thermoelectric applications for clean energy conversion. ${ }^{1-8}$ Misfit layered compounds (MLC) can be considered to be composite materials made by assembling two different kinds of layers, which have different crystal structure and lattice parameters. ${ }^{1}$ The properties of the composite structure vary from that of the individual components due to mutually incommensurate structural modulation that is imposed by one layer over the other to adjust to the difference in the crystal structure. The ability to modify each layer individually in misfit layered compounds can be very helpful for fine-tuning their properties and for the designing of advanced applications. Similar strategies have effectively been used to reduce the thermal conductivities of different misfit materials. ${ }^{4,9}$

Among these compounds, oxide-based MLCs have attracted significant interest over the last few years as promising thermoelectric materials ${ }^{5,10}$ that also show chemical and thermal stabilities at high temperatures. Calcium cobalt oxide $\left(\left[\mathrm{Ca}_{2} \mathrm{CoO}_{3}\right]\left[\mathrm{CoO}_{2}\right]_{1.62}\right.$ with the overall approximate composition $\mathrm{Ca}_{3} \mathrm{Co}_{4} \mathrm{O}_{9}$ ) is a well-studied material in this category. It consists of three-atom thick rocksalt type $\mathrm{Ca}_{2} \mathrm{CoO}_{3}$ layers sandwiched between edge-sharing octahedral $\mathrm{CoO}_{2}$ layers along the $c$-axis. ${ }^{11}$ In spite of being metallic, $\mathrm{Ca}_{3} \mathrm{Co}_{4} \mathrm{O}_{9}$ shows surprisingly high Seebeck coefficient $\left(\mathrm{S}_{300 \mathrm{~K}} \approx 125 \mu \mathrm{VK}^{-1}\right)$. Replacing $\mathrm{Ca}$ by $\mathrm{Sr}$ leads to $\left[\mathrm{Sr}_{2} \mathrm{CoO}_{3}\right]\left[\mathrm{CoO}_{2}\right]_{1.8}$ with the overall approximate composition $\mathrm{Sr}_{3} \mathrm{Co}_{4} \mathrm{O}_{9}$ that exhibits a somewhat reduced Seebeck coefficient $\left(\mathrm{S}_{300 \mathrm{~K}} \approx 110 \mu \mathrm{VK}^{-1}\right)^{12}$ but increased electrical conductivity thus considerably enhancing the overall thermoelectric power factor. ${ }^{13}$ But synthesizing those materials has been found to be very demanding because only 30 at $\%$ of $\mathrm{Sr}$ could be substituted in the host lattice of $\mathrm{Ca}_{3} \mathrm{Co}_{4} \mathrm{O}_{9} \cdot{ }^{13,14}$ However, the structure of $\mathrm{Sr}_{3} \mathrm{Co}_{4} \mathrm{O}_{9}$ can be 
stabilized by doping either Ge or Ti in the lattice. ${ }^{12}$ Later, Sakai et al. showed that, in fact, $\mathrm{Sr}_{3} \mathrm{Co}_{4} \mathrm{O}_{9}$ can be stabilized without any further doping after nanostructuration in thin-film form. ${ }^{13}$

It is well known that reducing the dimensionality of materials can improve their thermoelectric behavior significantly. ${ }^{15}$ Lately, there has been some notable progress in synthesizing such low-dimensional misfit compounds and studying their structure in onedimensional nanotubular form. ${ }^{16-21}$ Most of these reports deal with chalcogenide-based misfit compounds. However, very recently, a new route toward the synthesis of oxide-based misfit nanotubes were reported. ${ }^{22}$ In the first step of the reaction, the bulk $\mathrm{Ca}_{3} \mathrm{Co}_{4} \mathrm{O}_{9}$ compound was synthesized by thermally-activated reaction of the binary acetates of calcium and cobalt. The misfit structure of the bulk compound is depicted in Fig. 1a. It consists of alternating layers of three atom thick $\mathrm{Ca}_{2} \mathrm{CoO}_{3}(\mathrm{CaO}-\mathrm{CoO}-\mathrm{CaO})$ layers with a distorted rocksalt structure and hexagonal $\mathrm{CoO}_{2}$ edge-sharing octahedra (rhombohedrally distorted) layers along $c$-direction. The overall symmetry of the $\mathrm{Ca}_{3} \mathrm{Co}_{4} \mathrm{O}_{9}$ is monoclinic. The layers share a common $c$ - and $a$ axis, but are incommensurate along the $b$-axis. The ratio of the $b$-axes of the two sublattices is an irrational number. Therefore, the bulk compound has an approximate bulk composition represented by $\mathrm{Ca}_{3} \mathrm{Co}_{4} \mathrm{O}_{9}$. Recently, we have shown that hydrothermal treatment of the $\mathrm{Ca}_{3} \mathrm{Co}_{4} \mathrm{O}_{9}$ in basic conditions leads to abstraction of a $\mathrm{CaO}$ layer from the guest $\mathrm{Ca}_{2} \mathrm{CoO}_{3}$ layer yielding a new guest layer of the composition $\mathrm{CaCoO}_{2}$ intercalated into the host $\mathrm{CoO}_{2}$ layers (see schematic depiction in Fig. 1b). ${ }^{19}$ The Co atom in the newly formed $\mathrm{CaCoO}_{2}$ layer is 3-fold coordinated with the oxygen atoms in a trigonal monopyramidal fashion. The $\mathrm{Ca}$ atoms bonds with the corresponding oxygen atoms thus this structure can be viewed as a quasi-1D, puckered chains along the $a$-axis. However, no structural change is observed in the $\mathrm{CoO}_{2}$ edge-sharing octahedral arranged in hexagonal symmetry. This asymmetric structure lends itself to spontaneous scrolling, producing a new kind of misfit nanotube. Here again, 
the ratio of the $b$-axes of the two subunits is an irrational number. The approximate composition of the nanotubes $\left(\mathrm{CaCo}_{2.62} \mathrm{O}_{5.25}\right.$ or $\left.\mathrm{Ca}_{5} \mathrm{Co}_{13} \mathrm{O}_{26}\right)$ was obtained from the projection of the $(a-b)$ surface areas of the two subunits. Thus, the composition and structure of the nanotubes was found to be different from that of the bulk starting material. Detailed band structure calculations $^{19}$ indicated that while the bulk material is metallic, the nanotubes are semiconductors, thus holding promise for variety of applications. Misfit $\mathrm{Sr}_{3} \mathrm{Co}_{4} \mathrm{O}_{9}$ possess a similar crystal structure (see Figure $\mathbf{S 1 b}$ in supporting information) as $\mathrm{Ca}_{3} \mathrm{Co}_{4} \mathrm{O}_{9}$ with lattice periodicity of $1.08 \mathrm{~nm}$ along the $c$-axis. However, the analogous Sr-based nanotubes, $\mathrm{SrCoO}_{2}-\mathrm{CoO}_{2}$, have not been synthesized so far. In spite of little lower Seebeck coefficient of bulk $\mathrm{Sr}_{3} \mathrm{Co}_{4} \mathrm{O}_{9}$ compared to bulk $\mathrm{Ca}_{3} \mathrm{Co}_{4} \mathrm{O}_{9}$, strontium cobaltite offers superior thermoelectric properties over bulk calcium cobaltite, due to lesser resistivity values of $\mathrm{Sr}_{3} \mathrm{Co}_{4} \mathrm{O}_{9}$ that increases the overall power factor. Similarly, we anticipate similar enhancement of thermoelectric properties in the lower band gap Sr-based nanotubes, providing the impetus for this work.

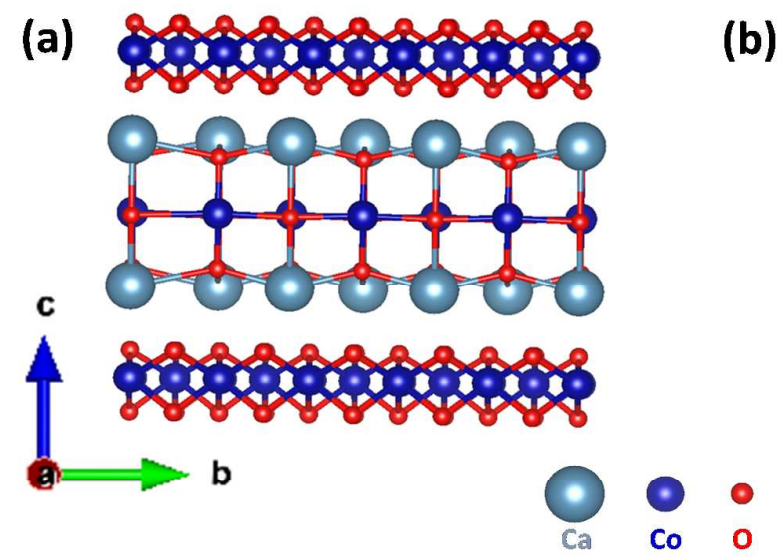

(b)

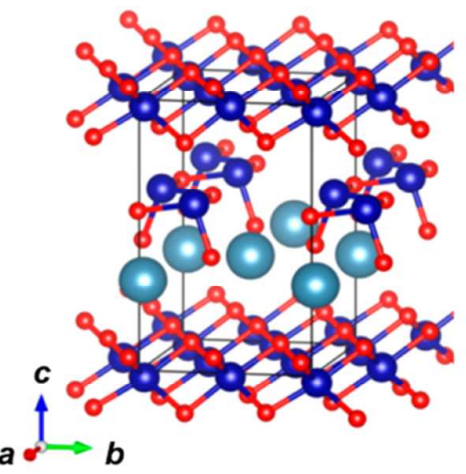

Figure 1. Schematic representation of the crystal structure of (a) bulk $\mathrm{Ca}_{3} \mathrm{Co}_{4} \mathrm{O}_{9}$ $\left(\mathrm{Ca}_{2} \mathrm{CoO}_{3}-\mathrm{CoO}_{2}\right)$, (b) crystal structure of $\mathrm{CaCoO}_{2}-\mathrm{CoO}_{2}$ in nanotubular form- rearrangement of atoms after removal of $\mathrm{CaO}$ layer from $\mathrm{Ca}_{2} \mathrm{CoO}_{3}-\mathrm{CoO}_{2}$ 
In this paper, we use strategies analogous to our previous work ${ }^{20}$ to prepare $\mathrm{SrCoO}_{2}$ $\mathrm{CoO}_{2}$ misfit nanotubes and nanoscrolls, starting from the bulk $\mathrm{Sr}_{2} \mathrm{CoO}_{3}-\mathrm{CoO}_{2}$ misfit compound. Thorough structural studies are conducted by various electron microscopy techniques, including electron diffraction, aberration corrected high-resolution (scanning) transmission electron microscopy (HR-(S)TEM) and electron energy-loss spectroscopy (EELS). The structural information gathered at the nanoscale by these TEM techniques are found to be in excellent agreement with density functional theory (DFT) simulations. Furthermore, DFT also shed light on the electronic and magnetic properties of the nanotubes, and show that these structures are ferrimagnetic semiconductors unlike the metallic bulk phase.

\section{EXPERIMENTAL SECTION}

SrCoO-CoO $\mathrm{C}_{2}$ nanotubes were synthesized by a procedure similar to the hydrothermal method described in Ref. ${ }^{22}$. Strontium acetate (Sigma-Aldrich, 99.995\%) and cobalt acetate tetrahydrate, (Alpha Aesar, >98\%) were dissolved in milli Q water in 3:4 ratios and heated at $90{ }^{\circ} \mathrm{C}$ until formation of a gel. The gel was placed in a furnace, which was preheated to 900 ${ }^{\circ} \mathrm{C}$, and held at that temperature for $12 \mathrm{~h}$ before cooling down to room temperature to obtain the bulk $\mathrm{Sr}_{3} \mathrm{Co}_{4} \mathrm{O}_{9}$ phase, i.e. the misfit structure $\mathrm{Sr}_{2} \mathrm{CoO}_{3}-\mathrm{CoO}_{2}$. The nanotubes were obtained by the hydrothermal treatment of the bulk $\mathrm{Sr}_{3} \mathrm{Co}_{4} \mathrm{O}_{9}$ structure in basic conditions. In a typical synthesis, $100 \mathrm{mg}$ of $\mathrm{Sr}_{3} \mathrm{Co}_{4} \mathrm{O}_{9}$ was sonicated for $10 \mathrm{~min}$ in $17 \mathrm{ml} \mathrm{NaOH}$ solution $(0.75 \mathrm{M})$. To check the influence of this parameter, the synthesis was repeated with two other $\mathrm{NaOH}$ concentrations: 1.5 and $2 \mathrm{M}$. The supernatant was then hydrothermally treated in Teflon lined autoclave at $200^{\circ} \mathrm{C}$ for $12 \mathrm{~h}$ before it naturally cooled down to room temperature. The final powder product was washed several times with Milli Q water and centrifuged to become $\mathrm{pH} \sim 7$, and finally dried in vacuum. 
A Rigaku diffractometer (TTRAX III) was used for the X-Ray diffraction (XRD) analysis. Scanning electron microscope (SEM) images were taken using Ultra V55 Zeiss SEM. Conventional selected-area electron-diffraction and high-resolution TEM studies were carried out with Philips CM120 TEM, operating at $120 \mathrm{kV}$, which is equipped with EDS detector (EDAX-Phoenix Microanalyzer) and JEOL JEM2100 operating at $200 \mathrm{kV}$. Advanced high-resolution STEM imaging (HR-STEM) and spatially-resolved electron energy-loss spectroscopy (SR-EELS) were performed using a FEI Titan Low-Base microscope, operated at $200 \mathrm{kV}$, and equipped with a Cs probe corrector, a monochromator, an ultra-bright X-FEG electron source, and a Gatan Tridiem ESR 865 EELS spectrometer. HR-STEM imaging was performed by using an annular dark field (ADF) detector. The probe convergence semi-angle was equal to $25 \mathrm{mrad}$ and the inner and outer angles for ADF imaging were 27 and $152 \mathrm{mrad}$, respectively. Before each measurement, the spatial calibration of the microscope was controlled by using a reference sample of gold nanoparticles. ADF image simulations were performed by using the multislice Dr. Probe software $^{23}$ and by using the experimental settings of the Titan Low Base as inputs. The calculations were done in the frozen-lattice approximation. For each slice, 30 frozen lattice states, created by introducing random atomic displacements, were computed in order to take into account thermal diffuse scattering. The energy resolution during SR-EELS investigations was about $2 \mathrm{eV}$, with a dispersion of $0.52 \mathrm{eV} /$ pixel. For most of the EELS experiments, the convergence and collection angles were 18 and $17 \mathrm{mrad}$, respectively. The EELS datasets were then de-noised with the open-source program Hyperspy ${ }^{24,25}$ by using principal component analysis routines and submitted to the open-access EELS Database ${ }^{26}$ as references.

\section{Computational Methods}


Density functional theory (DFT) calculations were performed using the Vienna Ab Initio Simulation Package (VASP). ${ }^{27,28}$ The projector-augmented wave method ${ }^{29,30}$ was used to represent $\mathrm{Sr}, \mathrm{Co}$ and $\mathrm{O}$ atoms with valence electronic configurations of $4 s^{2} 4 p^{6} 5 s^{2}, 3 d^{8} 4 s^{1}$, and $2 s^{2} 2 p^{4}$, respectively. A kinetic energy cutoff of $525 \mathrm{eV}$ was employed along with a $\Gamma$ centered $13 \times 13 \times 6 \mathrm{k}$-point mesh for Brillouin zone sampling, which is sufficient to converge the total energy to within $1 \mathrm{meV}$. A Gaussian smearing of $0.05 \mathrm{eV}$ was used to accelerate electronic convergence. Electronic wavefunctions were converged to $10^{-4} \mathrm{eV}$. The PerdewBurke-Ernzerhof (PBE) form of the generalized-gradient approximation was used to describe electron exchange and correlation. ${ }^{31}$ The rotationally-invariant DFT+U approach of Dudarev et al. ${ }^{32}$ was applied to treat the strongly correlated $d$-electrons of Co with onsite corrections of $U=5 \mathrm{eV}$ and $J=1 \mathrm{eV}$, which have been successfully employed before for calcium and strontium cobaltites. ${ }^{33,34}$ Atomic positions and cell vectors were relaxed with force and pressure tolerances of $0.01 \mathrm{eV} / \AA$ and $1 \mathrm{kbar}$, respectively. After structural relaxation, electronic wavefunctions, density of states, and charge and spin densities were recalculated using the Blöchl tetrahedron method ${ }^{35}$ (0.05 eV smearing). Charge and spin distributions were projected on to atomic volumes using the Bader analysis procedure. ${ }^{36,37}$

$\mathrm{DFT}+\mathrm{U}$ calculations can often get trapped in different local minima resulting in varying predictions of atomic spin states and magnetic configurations. ${ }^{38,39}$ Therefore, we initialized our calculations with multiple low- and high-spin states of Co atoms and performed complete structural relaxations of these various starting configurations to identify the most likely magnetic ground state.

\section{RESULTS AND DISCUSSION}

The reaction of strontium acetate and cobalt acetate in the $3: 4$ ratio at $900{ }^{\circ} \mathrm{C}$ yielded $\mathrm{Sr}_{3} \mathrm{Co}_{4} \mathrm{O}_{9}(\mathrm{SCO})$ bulk compound. The XRD patterns of the product are shown in Fig. S1 in the supporting information and confirm the formation of $\mathrm{Sr}_{3} \mathrm{Co}_{4} \mathrm{O}_{9}$ as a major phase along 
with hexagonal $\mathrm{Sr}_{6} \mathrm{Co}_{5} \mathrm{O}_{15}$ as a minor product. Hydrothermal treatment of the above product in basic conditions yields nanotubes in appreciable quantities as shown by the low and high magnification SEM images (Fig. 2a and 2b). The yield of the nanotubes in this procedure was around $70 \%$. Nanotubes synthetized with an $\mathrm{NaOH}$ concentration of $0.75 \mathrm{M}$ are typically $200 \mathrm{~nm}$ long, and are $40 \mathrm{~nm}$ and $22 \mathrm{~nm}$ in their external and internal diameters, respectively. Nanotubes synthetized with higher $\mathrm{NaOH}$ concentration tend to have a greater length $(\sim 300$ $\mathrm{nm}$ ) and smaller diameters (25 and $15 \mathrm{~nm}$ for their external and internal diameter, respectively). This shows that the $\mathrm{NaOH}$ concentration strongly affects the morphology of the nanotubes as well as their crystallinity. Fig. 2c shows the TEM image of the $\mathrm{SrCoO}_{2}-\mathrm{CoO}_{2}$ nanotubes containing hollow core with uniform diameter throughout the tubes of about $25 \mathrm{~nm}$ and with wall thickness of $\sim 5 \mathrm{~nm}$.
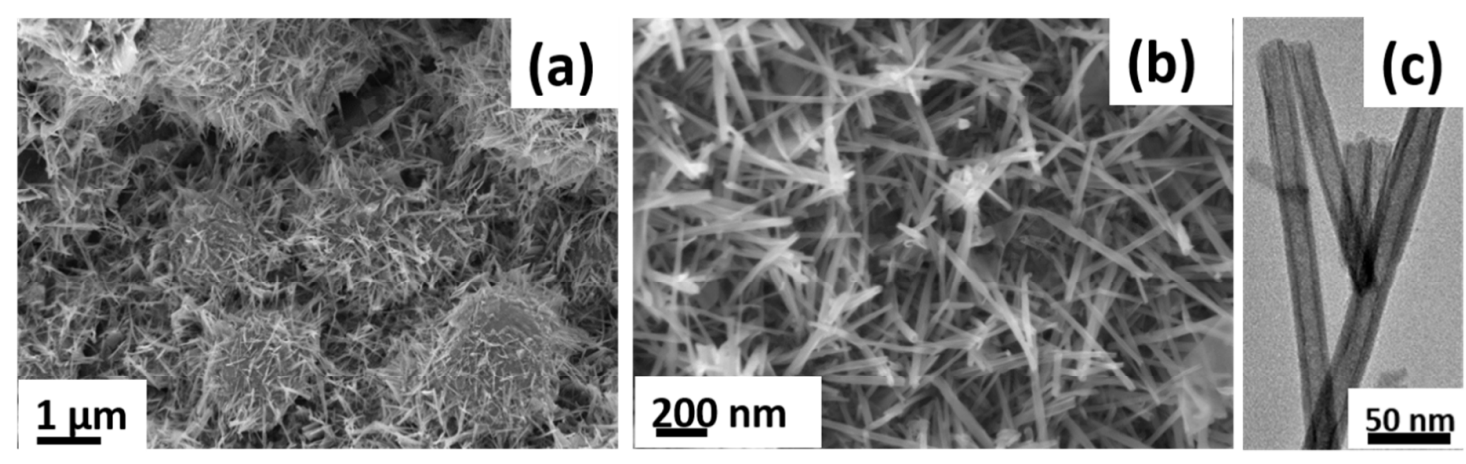

Figure 2. ((a) and (b)) SEM and (c) TEM images of as synthesized $\mathrm{SrCoO}_{2}-\mathrm{CoO}_{2}$ nanotubes.

It has been commonly observed that the inner diameters of the $\mathrm{SrCoO}_{2}-\mathrm{CoO}_{2}$ nanotubes are smaller than that of $\mathrm{CaCoO}_{2}-\mathrm{CoO}_{2}$ nanotubes synthesized under similar conditions (see Ref. ${ }^{22}$ ). In the case of nanotubes synthesized from lanthanide-based misfit compounds (LnS$\mathrm{CrS}_{2}$, where $\mathrm{Ln}=\mathrm{La}, \mathrm{Ce}, \mathrm{Gd}$ and $\mathrm{Tb}$ ), the diameters of the nanotubes decrease from La to $\mathrm{Tb}$ 
under similar reaction conditions. ${ }^{17,40}$ These observations suggest that nanotubes synthesized from heavier atoms lend themselves to smaller radii of curvature as compared to those with lighter atoms.
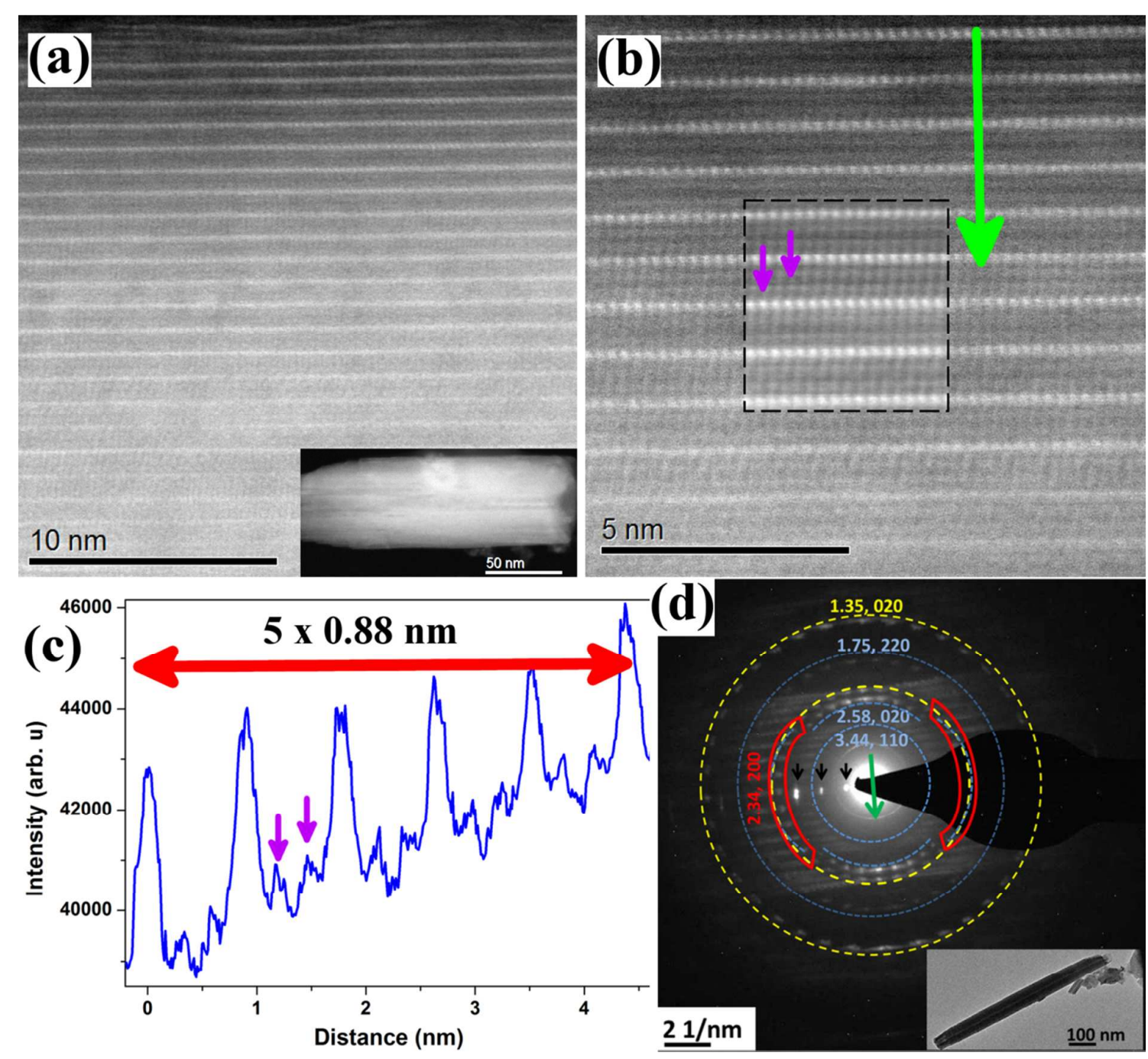

Figure 3 (a) HR-STEM ADF micrograph of one NT synthetized with a $\mathrm{NaOH}$ concentration of $0.75 \mathrm{M}$. The inset shows the corresponding low-magnification micrograph. (b) HR-STEM ADF micrograph of the upper edge of the nanotube. The dotted area corresponds to the filtered image. The green arrow indicates the area from which the intensity profile in (c) was obtained. The purple arrows highlight the two atomic layers sandwiched between the bright layers. (d) SAED pattern of an oxide-based strontium NT. A low magnification TEM image of the same nanotube is shown as an inset. The tubular axis and basal reflections are marked with green and black arrows, respectively. Spots corresponding to the same interplanar spacings are marked by dashed circles and measured values, with the corresponding Miller indices, specified. Blue and yellow colors indicate the $\mathrm{SrCoO}_{2}$ and $\mathrm{CoO}_{2}$ sub-systems respectively. The red color indicates spots originating from both sub-systems. 
An HR-STEM micrograph of one oxide-based strontium NT, synthetized with a $\mathrm{NaOH}$ concentration of $0.75 \mathrm{M}$, is shown in Fig. 3a. The walls of the nanotube are clearly visible and the nanotube shows a high degree of crystallinity. Going from the surface towards the center, an alternation of bright layers can be highlighted (Fig. 3b and 3c). After a thorough spatial calibration with a reference sample, the bright layer interspacing is estimated to be $0.88 \pm 0.02 \mathrm{~nm}$. This value is significantly smaller than the one displayed by the bulk misfit strontium cobaltite $\mathrm{Sr}_{3} \mathrm{Co}_{4} \mathrm{O}_{9}(1.08 \mathrm{~nm})$. Between two bright layers, two other layers of weaker intensities can be seen in the micrograph and in the corresponding intensity profile (see purple arrows in Fig. 3 c). The value of the bright layer interspacing and the number of layers in the structure suggest that the nanostructuring of the bulk strontium cobaltite follows the same scenario as the $\mathrm{Ca}$ counterpart, i.e., one $\mathrm{SrO}$ layer is removed from the bulk structure. Fig. 3d shows the SAED pattern of a nanotube along with the corresponding TEM image as an inset. The green and black arrows in Fig. 3d indicate tubular axis and basal reflections, respectively. Blue- and yellow-segmented circles indicate spots originating from the $\mathrm{SrCoO}_{2}$ and $\mathrm{CoO}_{2}$ sub-systems, respectively. The superstructure of alternating $\mathrm{SrCoO}_{2}$ and $\mathrm{CoO}_{2}$ layers has again a periodicity of $0.87 \mathrm{~nm}$. Due to the mutual structural modulation in misfit layer compounds, the rocksalt layer generally tends to adapt to the hexagonal layer. Therefore, the pseudohexagonal $\mathrm{CoO}_{2}$ unit cell can be defined as an ortho-hexagonal unit cell with lattice parameter $a, b=\sqrt{ } 3 a$ and $c$. There are 36 spots of $\{110\}$ and $\{220\}$ reflections of $\mathrm{SrCoO}_{2}$ on a circle, equal azimuthally distributed with $d$-spacings of 3.44 and $1.75 \AA$, respectively. Furthermore, the diffraction spots are streaked suggesting a scroll-like structure rather than a nanotube in this case. There are 36 spots of $\{200\}$ and $\{020\}$ reflections of $\mathrm{CoO}_{2}$ equally distributed azimuthally on the circle with $d$-spacings of 2.34 and $1.35 \AA$ respectively. The $a$-directions of $\mathrm{SrCoO}_{2}$ and $\mathrm{CoO}_{2}$ are parallel, and the lattice parameters are 
commensurate in this direction. Thus, the 18 spots corresponding to the reflections of the $\{200\}$ planes with a $d$-spacing of $2.34 \AA$ originate from both the $\mathrm{SrCoO}_{2}$ and the $\mathrm{CoO}_{2}$ layers (shown in red). There are also 18 spots of $\{020\}$ reflections of $\mathrm{SrCoO}_{2}$ with $d$-spacing of 2.58 A. The indexing of the diffraction pattern confirms that one CoO layer is missing in the NT structure when compared to the bulk misfit structure. Therefore, the phase of the NT corresponds to $\mathrm{SrCoO}_{2}-\mathrm{CoO}_{2}$.
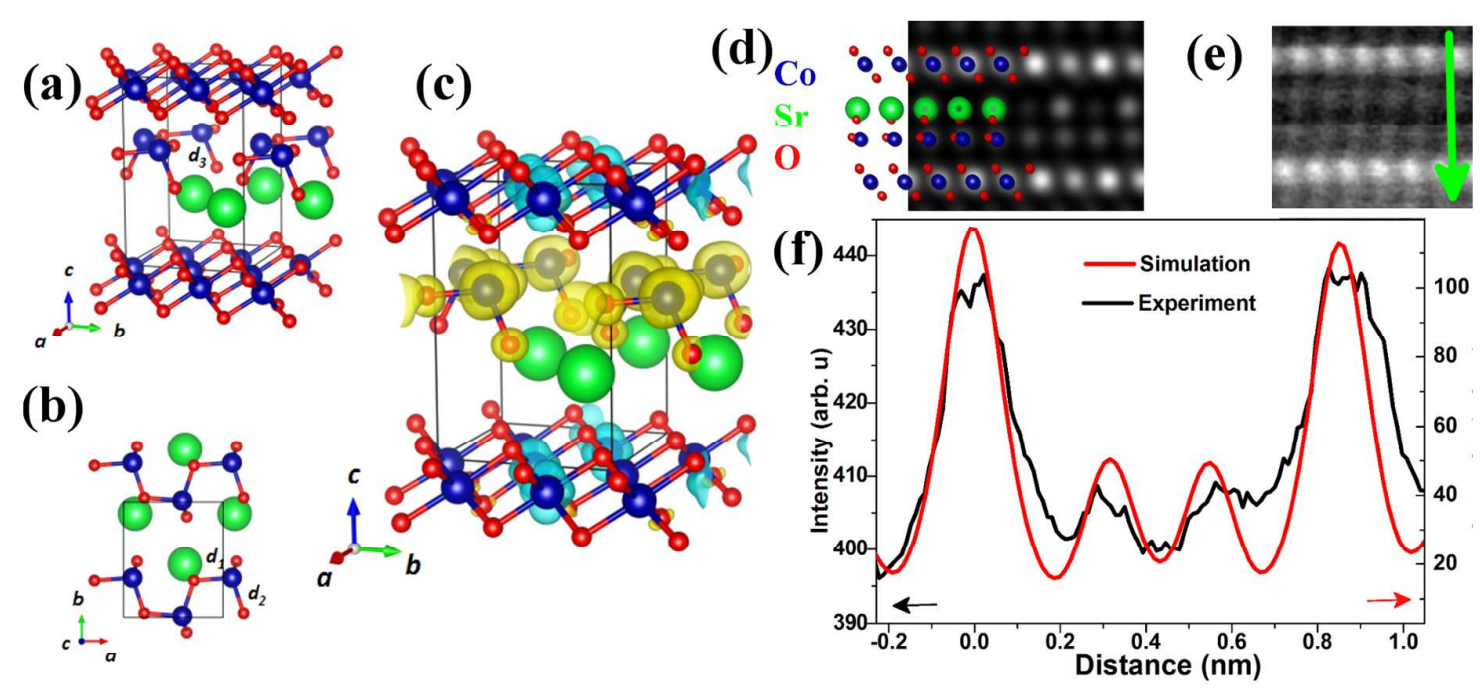

Figure 4: DFT-relaxed structure of (a) the $\left(\mathrm{SrCoO}_{2}\right)-\left(\mathrm{CoO}_{2}\right)_{2}$ supercell and (b) a top view of the $\mathrm{SrCoO}_{2}$ layer. $\mathrm{Sr}, \mathrm{Co}$ and $\mathrm{O}$ atoms are indicated by green, blue, and red spheres, respectively. The $\mathrm{Co}$ atoms in the $\mathrm{SrCoO}_{2}$ layer are threefold coordinated with staggered Co-O dimers $\left(d_{1}=1.89 \AA\right)$ that are nearly aligned along the $a$-axis with bridging Co-O bonds $\left(d_{2}=1.83 \AA\right)$ connecting parallel rows. The third Co-O bond $\left(d_{3}=1.79 \AA\right)$ is out of the $a$-b plane. (c) Isosurfaces of spin density (at $\left.0.13 \mathrm{e} / \AA^{3}\right)$ for the $\left(\mathrm{SrCoO}_{2}\right)-\left(\mathrm{CoO}_{2}\right)_{2}$ supercell. Yellow/cyan colors indicate positive/negative magnetic moments. The Co atoms within either the $\mathrm{SrCoO}_{2}$ or $\mathrm{CoO}_{2}$ layer are ferromagnetically coupled while the two layers themselves are antiferromagnetically coupled leading to an overall ferrimagnetic ground state. (d) Simulated HR-STEM ADF micrograph superposed with the relaxed atomic structure of $\mathrm{SrCoO}_{2}-\mathrm{CoO}_{2}$ used as input. (e) Experimental STEM ADF image. The green arrow highlights the direction used to determine the (f) experimental and simulated line profiles extracted from the images.

As shown above in our experimental characterization, the $\mathrm{SrCoO}_{2}-\mathrm{CoO}_{2}$ phase consists of two layers that are commensurate along the $a$-axis $(4.68 \AA)$ but incommensurate along the $b$ axis $\left(b_{\mathrm{SrCoO} 2}=5.16 \AA, b_{\mathrm{CoO} 2}=2.70 \AA\right)$. Therefore, we created a simulation supercell with 
composition $\left(\mathrm{SrCoO}_{2}\right)_{\mathrm{b} 1}-\left(\mathrm{CoO}_{2}\right)_{\mathrm{b} 2}$ where the periodicities of each subsystems along the $b$ axis were chosen to be $b_{1}=1$ and $b_{2}=2$. The resulting mismatch strain between the two subsystems is approximately $4.5 \%$, which is comparable to the mismatch strains as in other commonly studied structures such as the $3 / 2$ rational approximant of calcium cobaltite. ${ }^{41}$ The initial structure of the $\mathrm{SrCoO}_{2}$ layer was produced by replacing the $\mathrm{Ca}$ atoms of the analogous relaxed structure for $\mathrm{CaCoO}_{2}$, reported in our previous work, ${ }^{22}$ with $\mathrm{Sr}$. We note that the structures being simulated here are bulk-like and hence, effects of nanotube curvature and 1D quantum confinement are not captured in the electronic structure. Nevertheless, to the extent that the synthesized nanotubes have fairly large diameters and are thick-walled, the calculated electronic properties are expected to be reasonably representative of these systems.

Starting from the initial structure discussed above, we performed DFT $+\mathrm{U}$ structural relaxation calculations and obtained the optimized structures displayed in Figures 4a and $\mathbf{4 b}$ (see Table S1 in the SI for atomic coordinates and lattice parameters). Similar to the case of $\mathrm{CaCoO}_{2},{ }^{22}$ the $\mathrm{SrCoO}_{2}$ layer also displays a cluster-like structural pattern when viewed along the $a$-axis. The $\mathrm{Co}$ atoms of the $\mathrm{SrCoO}_{2}$ layer are threefold coordinated with the $\mathrm{O}$ atoms: staggered Co-O dimers (1.89 $\AA$ ) are arranged (nearly) parallel to the $a$-axis and are connected by bridging Co-O bonds $(1.83 \AA)$; the third Co-O bond is out of plane $(1.79 \AA)$ and the corresponding $\mathrm{O}$ atom is also coordinated with a $\mathrm{Sr}$ atom. Thus, the overall structure of the $\mathrm{SrCoO}_{2}$ layer may be viewed as a collection of puckered, quasi-1D $\left(\mathrm{CoO}_{2}\right)^{2-}$ units that are coordinated with $\mathrm{Sr}^{2+}$ ions. The $\mathrm{CoO}_{2}$ layer retains the same structure as in the parent $\mathrm{Sr}_{3} \mathrm{Co}_{4} \mathrm{O}_{9}$ phase. To confirm this new structure, we have performed a multislice calculation of the HR-STEM ADF micrograph (Fig. 4d). This calculation has been developed using the DFT-relaxed structure as input. Fig. 4d and $4 \mathbf{e}$ displays the comparison between this simulation and the experimental image. The agreement between the experimental and simulated intensity profiles, extracted from these figures (see Fig. 4f), is excellent. The 
bright-layer interspacing, corresponding to the distance between the $\mathrm{CoO}_{2}$ layers, is equal to $0.86 \mathrm{~nm}$ and $0.88 \pm 0.02 \mathrm{~nm}$, for the simulated and experimental image, respectively. In addition to the consistency of the position of all the layers, the respective intensities of the $\mathrm{CoO}_{2}$ layers with regards to the intensities of the two layers of weaker intensities in-between (corresponding to the $\mathrm{SrO}$ and $\mathrm{CoO}$ layers) is well-reproduced. This excellent agreement between modeling and experiment allows us to use the DFT-relaxed structure for further studies of electronic and magnetic properties of this new $\left(\mathrm{SrCoO}_{2}\right)-\left(\mathrm{CoO}_{2}\right)_{2}$ phase.

The electronic density of states (DOS) for the $\left(\mathrm{SrCoO}_{2}\right)-\left(\mathrm{CoO}_{2}\right)_{2}$ structure is displayed in Fig. S2a in the supporting information. Unlike bulk strontium cobaltite which is metallic, ${ }^{34}$ and similar to the $\left(\mathrm{CaCoO}_{2}\right)-\left(\mathrm{CoO}_{2}\right)_{2}$ phase, ${ }^{22}$ we observe that $\left(\mathrm{SrCoO}_{2}\right)-\left(\mathrm{CoO}_{2}\right)_{2}$ is semiconducting. The calculated $\mathrm{PBE}+\mathrm{U}$ band gap for the majority spin channel is $\sim 0.78 \mathrm{eV}$ while that for the minority spin channel is $\sim 1.06 \mathrm{eV}$, which are both smaller by about $0.3 \mathrm{eV}$ than the previously reported gaps for $\left(\mathrm{CaCoO}_{2}\right)-\left(\mathrm{CoO}_{2}\right)_{2}(1.19 \mathrm{eV}$ and $1.30 \mathrm{eV}$, respectively, for majority and minority spin channels). ${ }^{22}$ The overall magnetic moment for the entire supercell is calculated to be $6 \mu_{\mathrm{B}}$. As seen from the spin density distribution in Figure 4(c) though, there are positive magnetic moments on all $\mathrm{Co}$ atoms in the $\mathrm{SrCoO}_{2}$ layer and localized negative magnetic moments on every other $\mathrm{Co}$ atom in the $\mathrm{CoO}_{2}$ layer. A more quantitative estimate is obtained by integrating the spin density over the Bader volumes (see Table S1 in SI) from which we find that each Co atom in the $\mathrm{SrCoO}_{2}$ layer possesses a magnetic moment of $3.01 \mu_{\mathrm{B}}$, which is consistent with a high-spin $\mathrm{Co}^{2+}$ oxidation state. Similarly, the $\mathrm{Co}$ atoms in the $\mathrm{CoO}_{2}$ layer possess a magnetic moment of $-1.19 \mu_{\mathrm{B}}$ or $0.03 \mu_{\mathrm{B}}$; these moments are consistent with the $\mathrm{Co}$ atoms being in mixed-valence $\mathrm{Co}^{3+}$ and $\mathrm{Co}^{4+}$ lowspin states analogous to the results of Rébola et al. ${ }^{41}$ for bulk calcium cobaltite and our previous results for $\left(\mathrm{CaCoO}_{2}\right)-\left(\mathrm{CoO}_{2}\right)_{2} \cdot{ }^{22}$ Overall, the intralayer magnetic coupling in both 
the $\mathrm{SrCoO}_{2}$ and $\mathrm{CoO}_{2}$ layers is ferromagnetic whereas the interlayer coupling is antiferromagnetic, leading to net ferrimagnetic ground state.

Up to this point, the electronic and magnetic properties of $\left(\mathrm{SrCoO}_{2}\right)-\left(\mathrm{CoO}_{2}\right)_{2}$ that we have discussed are almost identical to $\left(\mathrm{CaCoO}_{2}\right)-\left(\mathrm{CoO}_{2}\right)_{2}$. However, as the $5 \mathrm{~s}$ electrons of $\mathrm{Sr}$ are more loosely bound than the $4 \mathrm{~s}$ electrons of $\mathrm{Ca}$, one might expect quantitative differences in charge transfer between $\mathrm{SrCoO}_{2}$ and $\mathrm{CoO}_{2}$ layers relative to the $\mathrm{CaCoO}_{2}$ variant. $\mathrm{By}$ summing the Bader charges over the $\mathrm{SrCoO}_{2}$ and $\mathrm{CoO}_{2}$ layers (see Table $\mathrm{S} 1$ in $\mathrm{SI}$ ), we find a net transfer of $1.68 \mathrm{e}^{-}$from the $\mathrm{SrCoO}_{2}$ layer to the $\mathrm{CoO}_{2}$ layer. The $\mathrm{Sr}$ atoms donate a total of $3.2 \mathrm{e}^{-}$of which $1.52 \mathrm{e}^{-}$are redistributed within the $\mathrm{SrCoO}_{2}$ layer and $1.68 \mathrm{e}^{-}$are transferred to the $\mathrm{CoO}_{2}$ layer $\left(0.42 \mathrm{e}^{-}\right.$per formula unit). Thus, similar to the Ca case, charge transfer from the $\mathrm{SrCoO}_{2}$ layer to the $\mathrm{CoO}_{2}$ layer leads to the mixed valence $\mathrm{Co}^{3+} / \mathrm{Co}^{4+}$ state of $\mathrm{Co}$ atoms in the $\mathrm{CoO}_{2}$ layer. In comparison with our previously reported results for $\mathrm{CaCoO}_{2}-\mathrm{CoO}_{2}$ (Ref. 20 and SI) we find a nearly similar degree (to within numerical error) of charge transfer to the $\mathrm{CoO}_{2}$ layer in the present case.

Overall, we conclude from our DFT $+\mathrm{U}$ studies that the $\mathrm{SrCoO}_{2}-\mathrm{CoO}_{2}$ phase is fairly similar to the $\mathrm{CaCoO}_{2}-\mathrm{CoO}_{2}$ phase in its electronic and magnetic properties, the main difference between the two materials being the smaller band gap for the former (by $\sim 0.3 \mathrm{eV}$ ). It is also possible that more substantial differences could arise in the transport behavior due to differences in scattering of charge carriers from $\mathrm{Sr}$ and $\mathrm{Ca}$ atoms as well as electron-phonon coupling in the two materials. In addition, calculations beyond the DFT level are needed to properly derive the optical properties of these two new materials. All of these questions will be investigated elsewhere. 

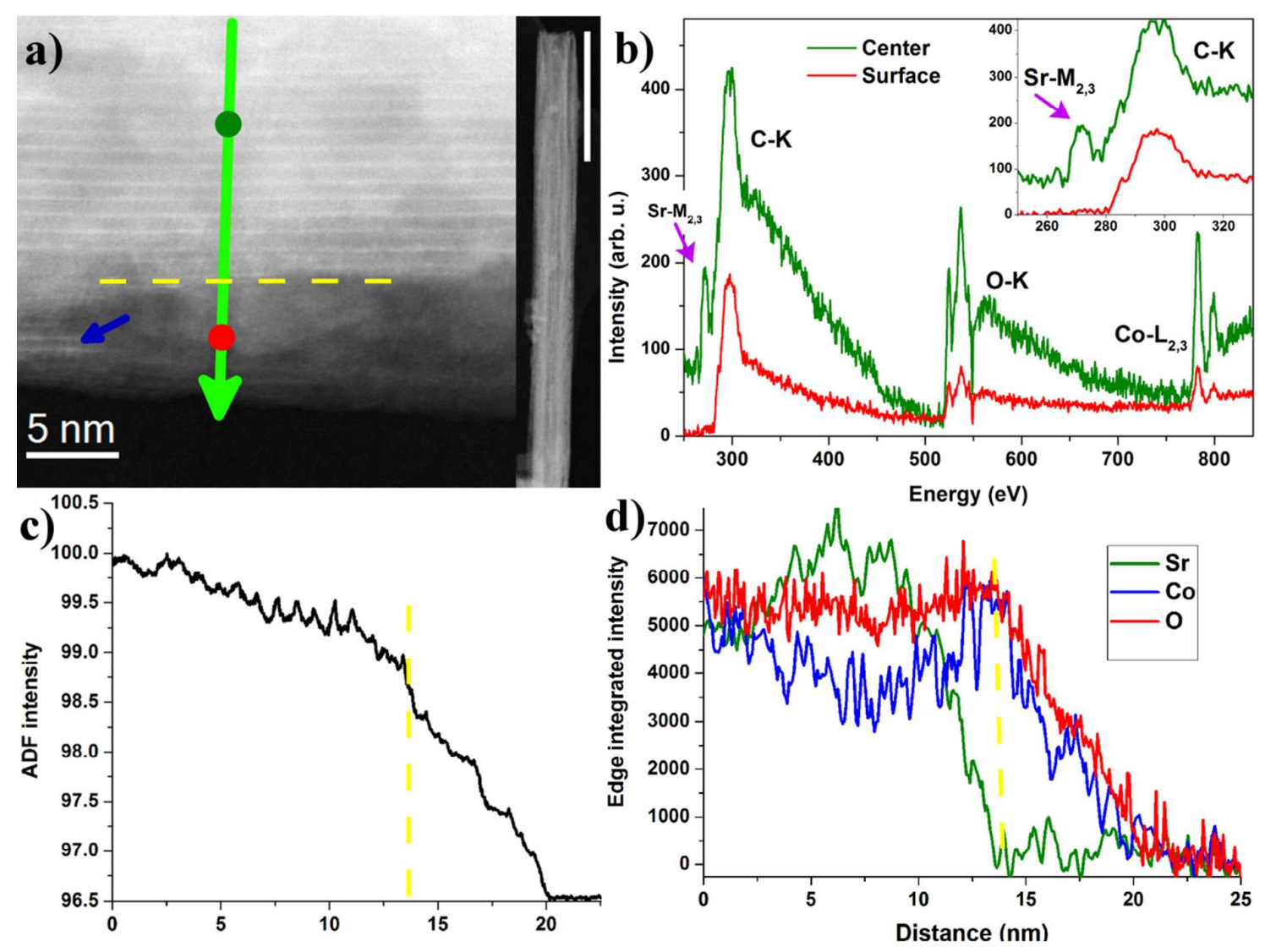

Figure 5. (a) (left) HR-STEM ADF micrograph of a $\mathrm{SrCoO}_{2}-\mathrm{CoO}_{2}$ nanotube synthesized with a $\mathrm{NaOH}$ concentration of $2 \mathrm{M}$. The green and red spots correspond to the areas in which the red and green EELS spectra of $5 b$ have been taken. The green arrow shows the path of the EELS scan line. The blue arrow highlights the presence of some atomic layers inside the outer layer. (right) Low-magnification micrograph of the same NT. The scale bar corresponds to $200 \mathrm{~nm}$. (b) EELS spectra taken at the surface and at the center of the NT. The purple arrows highlight the $\mathrm{Sr}-\mathrm{M}_{2,3}$ edge. (c) $\mathrm{ADF}$ intensity profile recorded along the path of the EELS scan line marked by a green arrow in $5 a$. (d) Results of the EELS scan line showing the integrated intensities of the $\mathrm{Sr}_{-} \mathrm{M}_{2,3}, \mathrm{O}-\mathrm{K}$ and $\mathrm{Co}-\mathrm{L}_{2,3}$ edges as a function of the distance. The yellow dotted lines in $\mathbf{5 a}, \mathbf{5} \boldsymbol{c}$ and $\mathbf{5} \boldsymbol{d}$ highlight the frontier between the core part of the NT and the outer layer of low crystallinity.

The driving force for rolling and unrolling in misfit-layered nanotubes or nanoscrolls is the material-dependent misfit strain in the structure. To further understand this point, we have studied the formation of nanotubes with different concentrations of $\mathrm{NaOH}$. The nanotubes synthetized with higher concentrations of $\mathrm{NaOH}$ (1.5 and $2 \mathrm{M}$ ) show a lower crystalline quality (See Figs. S3 and S4 in SI). In particular, the presence of exfoliated layers, stacking 
faults and an outer layer of low-crystallinity are noticeable. Fig. 5a shows an HR-STEM ADF micrograph of a NT synthetized with a $\mathrm{NaOH}$ concentration of $2 \mathrm{M}$. The core part of the nanotube (above the yellow dotted line in Fig. 5a) shows a good crystallinity and the alternation of $\mathrm{CoO}_{2}$ layers can be clearly seen. In this case, the $\mathrm{CoO}_{2}$ interspacing is equal to $0.87 \pm 0.02 \mathrm{~nm}$. This shows that, whatever the $\mathrm{NaOH}$ concentration, the nanotubes are synthetized in the same $\mathrm{SrCoO}_{2}-\mathrm{CoO}_{2}$ phase. The striking difference with nanotubes synthetized at lower $\mathrm{NaOH}$ concentration is the presence of an outer layer (below the yellow dotted line in Fig. 5a) of inferior crystallinity and whose thickness is between 10-15 nm. This layer is mostly amorphous, even if some atomic planes can be distinguished (blue arrow in Fig. 5a). To get some insight into the chemical nature of this outer layer, an EELS linescan was performed by going from the center of the nanotube toward the surface. EELS is an unrivaled tool to get a wealth of chemical information at the nanoscale ${ }^{25,42-45}$ and has already been successfully used to reveal the structure of other misfit nanotubes. ${ }^{21,22} \mathbf{F i g} . \mathbf{5 b}$ shows the EELS spectra taken in the core part and in the outer layer of the NT. In addition of to the C-K edge resulting from carbon surface contamination, the $\mathrm{O}-\mathrm{K}$ and $\mathrm{Co}-\mathrm{L}_{2,3}$ edges can be clearly seen revealed at 530 and $780 \mathrm{eV}$, respectively. In addition, one sharp peak situated at $260 \mathrm{eV}$ and belonging to the $\mathrm{Sr}-\mathrm{M}_{2,3}$ edge (see purple arrows in Fig. $\mathbf{5 b}$ and in the corresponding inset) can be highlighted in the core part of the NT, whereas it is absent in the outer layer. To check this point, the intensities of the $\mathrm{Sr}-\mathrm{M}_{2,3}, \mathrm{O}-\mathrm{K}$ and $\mathrm{Co}-\mathrm{L}_{2,3}$ edges were integrated along the whole scan line path and the results are displayed in Fig. 5d. By comparing this with the intensity profile of the ADF image (Fig. 5c), it can be clearly seen that the Sr is completely absent in the outer layer and that only the $\mathrm{Co}$ and $\mathrm{O}$ remain at the surface. This result is of importance as it shows that the $\mathrm{NaOH}$ solution leads to the dissolution and leaching of the $\mathrm{SrO}$ layers from the structure. This dissolution of the $\mathrm{SrO}$ layers from the lattice was found to be dependent on the reaction conditions. By increasing the concentration of $\mathrm{NaOH}$ in the 
reaction mixture, we found that more $\mathrm{Sr}$ ions are removed from the nanotubes. This explains why the product obtained at high concentration of $\mathrm{NaOH}$ (larger than $1.5 \mathrm{M}$ ) yields exfoliated nanotubes (see Fig. S3). Removal of the all $\mathrm{Sr}$ ions from the lattice (at high pHs) left only $\mathrm{CoO}_{2}$ sheets devoid of the misfit nanostructures. The observation of exfoliation of nanotubes signifies the importance of the misfit stress to keep the nanostructure tightly rolled into nanotubular/nanoscrolled form. In the absence of this driving force, nanotubes could not be obtained.
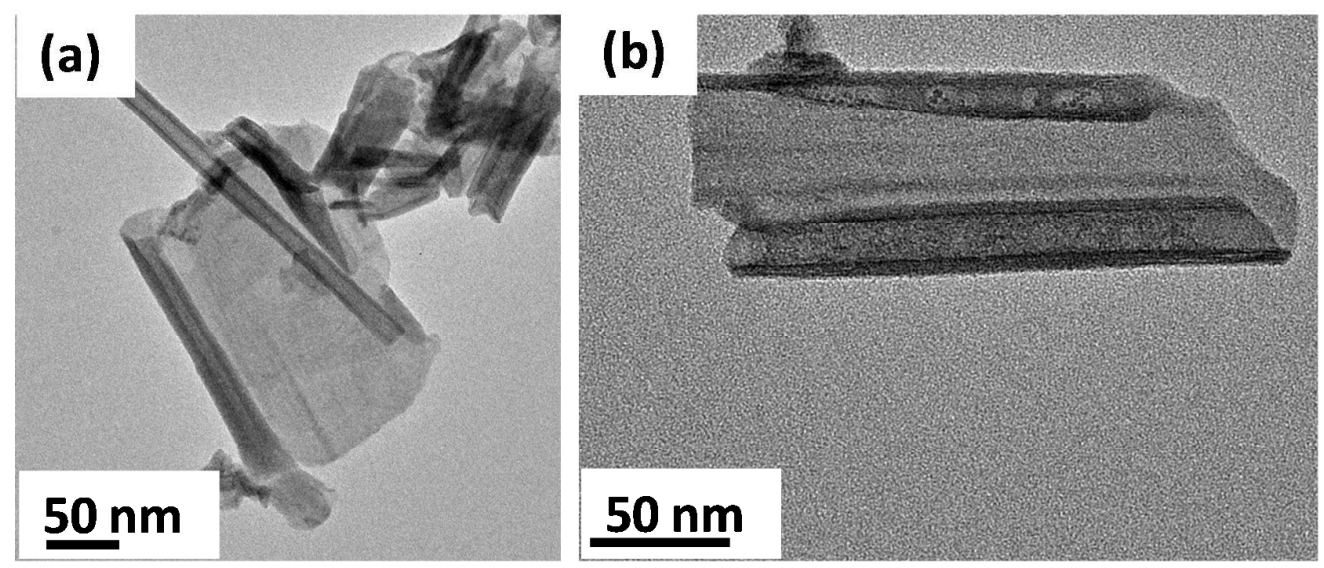

Figure 6. ((a) and (b)) TEM images of a partially rolled $\mathrm{SrCoO}_{2}-\mathrm{CoO}_{2}$ nanotubes synthesized in hydrothermal conditions at $200{ }^{\circ} \mathrm{C}$ for $4 \mathrm{~h}$.

To understand the growth mechanism of the misfit-layered nanotubes, systematic time dependent reactions were also conducted. Hydrothermal synthesis conducted for $1.5 \mathrm{~h}(0.75$ $\mathrm{M} \mathrm{NaOH}$ ) shows no nanotubes in the product, whereas reaction conducted for 4 hours shows nanotubes and partially rolled nanotubes in the product. Partially rolled nanotubes after $4 \mathrm{~h}$ of reaction are shown in Fig. 6. After 12 hours, the formation of the nanotubes is complete and no partially rolled structures are seen (Fig. 2). The observation of the partially-rolled structures at intermediate times suggests that the nanotubes are formed by exfoliation of the bulk layered structure. During the reaction process, one of the two SrO layers in the three 
atom thick rocksalt $\mathrm{Sr}_{2} \mathrm{CoO}_{3}$ layer is dissolved in the $\mathrm{NaOH}$. Apparently the removal of one SrO layer from the crystal structure perturbs the mechanical and possibly also the electrostatic force balance of the sandwich $\mathrm{CoO}_{2}-\mathrm{SrCoO}_{2}-\mathrm{CoO}_{2}$ structure. This force imbalance produces a compressive strain on the upper $\mathrm{CoO}_{2}$ layer and tensile strain on the opposite side inducing spontaneous rolling of the layer into a nanoscroll. A schematic representation of the growth mechanism is shown in Fig. 7. This kind of reaction mechanism has also been observed in solid-state thin films in the literature wherein thin films were observed to spontaneously roll into nanotubes upon being released from their substrates. ${ }^{46}$ Spontaneous rolling of sheets into nanotubes in asymmetric environment is known also in solution based synthesis process, like in the case of $\mathrm{H}_{2} \mathrm{Ti}_{3} \mathrm{O}_{7}{ }^{47}$ and $\mathrm{K}_{4} \mathrm{Nb}_{6} \mathrm{O}_{17}{ }^{48}$ nanotubes. However, in the present case along with crystal asymmetry created by removal of SrO layer, misfit stress between adjacent layers further promotes the rolling of the nanostructures. Most importantly, the misfit stress helps to keep the nanotubes tightly rolled in the solution phase. Furthermore, $\mathrm{Co}-\mathrm{O}$ bond in $\mathrm{Sr}_{2} \mathrm{CoO}_{3}$ experiences more tensile stress compared to $\mathrm{Co}-\mathrm{O}$ bond in $\mathrm{Ca}_{2} \mathrm{CoO}_{3}$ due to the longer bond length of $\mathrm{Co}-\mathrm{O}$ in former case. Due to this larger misfit stress, spontaneous formation of nanotubes of $\mathrm{Sr}_{2} \mathrm{CoO}_{3}-\mathrm{CoO}_{2}$ is more favorable (yield is $\sim 70 \%$ ) than the nanotubes from $\mathrm{Ca}_{2} \mathrm{CoO}_{3}-\mathrm{CoO}_{2}$ (yield $\sim 20-30 \%$ ). 


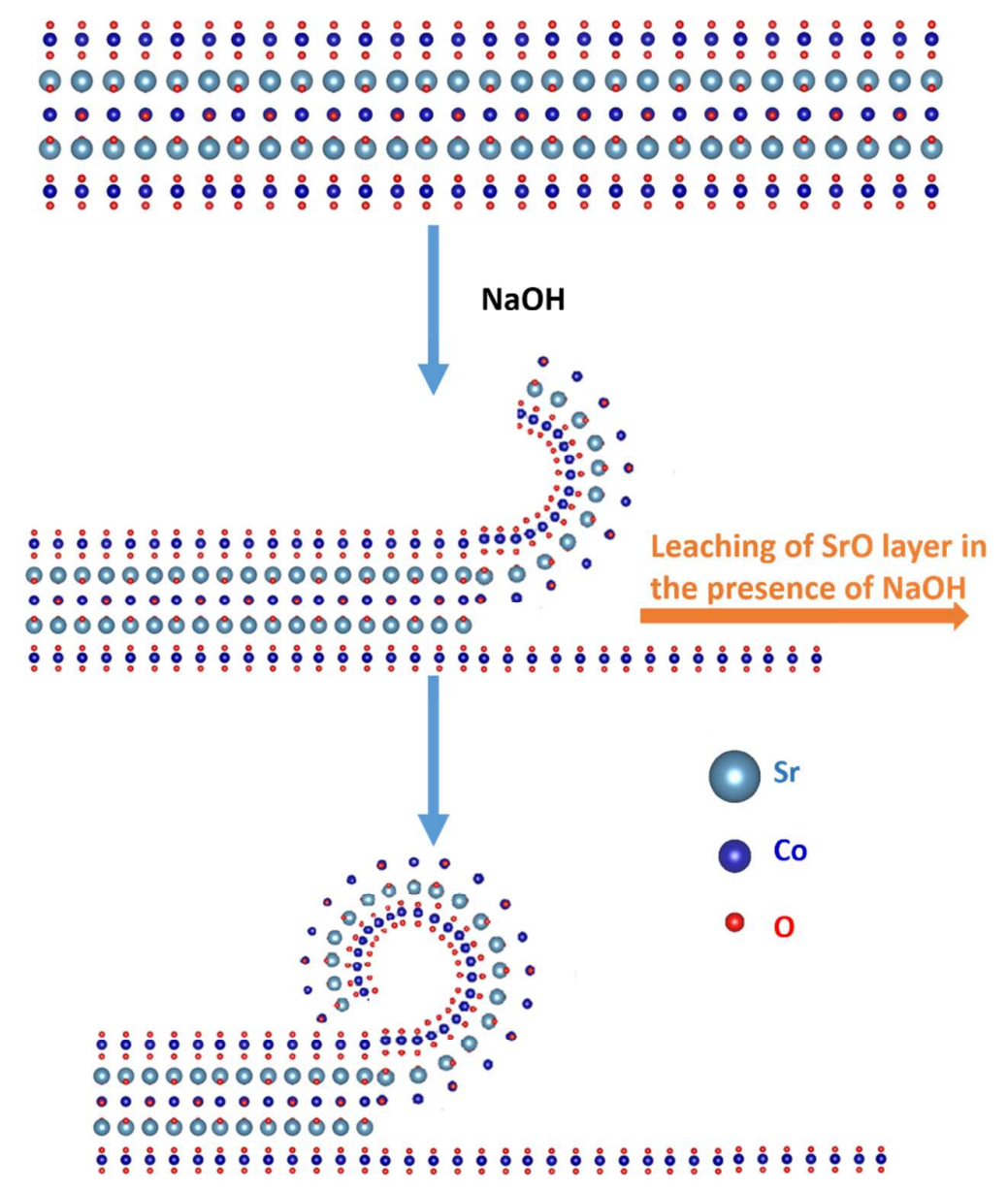

Figure 7. Schematic representation of formation of a nanoscroll by leaching of $\mathrm{SrO}$ in the presence of $\mathrm{NaOH}$.

\section{CONCLUSIONS}

Strontium-based misfit oxide nanotubes with alternating $\mathrm{SrCoO}_{2}$ and $\mathrm{CoO}_{2}$ layers were synthesized and characterized with electron microscopy and first-principles modeling. Hydrothermal synthesis of bulk $\mathrm{Sr}_{2} \mathrm{CoO}_{3}-\mathrm{CoO}_{2}$ under basic conditions is employed to yield the nanotubes. Dissolution of $\mathrm{SrO}$ from the bulk phase is confirmed by aberration corrected high-resolution (scanning) transmission electron microscopy and electron energy-loss spectroscopy. The resulting structure is found to consist of sandwich layers of $\mathrm{SrCoO}_{2}$ (may 
be viewed as a collection of puckered, quasi-1D $\left(\mathrm{CoO}_{2}\right)^{2-}$ units that are coordinated with $\mathrm{Sr}^{2+}$ ions) between the $\mathrm{CoO}_{2}$ layers. Unlike bulk $\mathrm{Sr}_{3} \mathrm{Co}_{4} \mathrm{O}_{9}\left(\mathrm{Sr}_{2} \mathrm{CoO}_{3}-\mathrm{CoO}_{2}\right)$, which is a metallic, $\mathrm{SrCoO}_{2}-\mathrm{CoO}_{2}$ is predicted to be semiconducting in nature with ferrimagnetic ground state. Thorough examination of the synthesis parameters have shown how to control the quality of these nanotubes which is crucial for a potential scale-up of their production. We anticipate that these low-dimensional misfit nanotubes could exhibit superior thermoelectric properties, relative to their bulk 3D counterparts, with potential applications for energy harvesting technologies.

\begin{abstract}
ASSOCIATED CONTENT
Supporting Information

XRD patterns of bulk $\mathrm{Sr}_{2} \mathrm{CoO}_{3}-\mathrm{CoO}_{2}$ along with schematic crystal structure; TEM images of a partially rolled $\mathrm{SrCoO}_{2}-\mathrm{CoO}_{2}$; TEM and HR-STEM ADF micrographs $\mathrm{SrCoO}_{2}-\mathrm{CoO}_{2}$ nanotubes synthesized at high concentration of $\mathrm{NaOH}$; Total density of states (DOS) for the $\left(\mathrm{SrCoO}_{2}\right)-\left(\mathrm{CoO}_{2}\right)_{2}$ supercell and its projection on to the $\mathrm{SrCoO}_{2}$ and $\mathrm{CoO}_{2}$ layers; Comparison of the total DOS for the $\left(\mathrm{SrCoO}_{2}\right)-\left(\mathrm{CoO}_{2}\right)_{2}$ supercell with that for the $\left(\mathrm{CaCoO}_{2}\right)-\left(\mathrm{CoO}_{2}\right)_{2}$ supercell.
\end{abstract}

This material is available free of charge via the Internet at http://pubs.acs.org.

\title{
AUTHOR INFORMATION
}

\section{Corresponding Authors}

*E-mail: arenal@unizar.es

*E-mail: ashwin@engin.umass.edu

*E-mail: panchakarla@chem.iitb.ac.in

Notes: The authors declare no competing financial interest. 


\section{Author Contributions}

${ }^{\perp}$ L. S. Panchakarla and L. Lajaunie contributed equally to this work

\section{ACKNOWLEDGMENTS}

We thank Dr. Y. Feldman for the X-ray diffraction analysis. The Israel Science Foundation (grant 265/12); the H. Perlman Foundation; the Irving and Azelle Waltcher Foundations in honor of Prof. M. Levy; and the Irving and Cherna Moskowitz Center for Nano and BioNano Imaging are acknowledged. L.S.P. acknowledges the PBC Program of the Government of Israel and the Dean of the chemistry faculty, Weizmann Institute of Science, for a postdoctoral fellowship. A.R. gratefully acknowledges computational support from the Massachusetts Green High Performance Computing Center as well as the University of Massachusetts Amherst. The TEM studies were conducted at the Laboratorio de Microscopias Avanzadas, Instituto de Nanociencia de Aragon, Universidad de Zaragoza, Spain. Some of the research leading to these results has received funding from the European Union Seventh Framework Program under Grant Agreement 312483 ESTEEM2 (Integrated Infrastructure Initiative - I3) and from the European Union H2020 program under the grant 696656 Graphene Flagship. R.A. gratefully acknowledges the support from the Spanish Ministry of Economy and Competitiveness (MINECO) through project grant FIS201346159-C3-3-P, from the Government of Aragon and the European Social Fund under the project "Construyendo Europa desde Aragon" 2014-2020 (grant number E/26), and from the European Union H2020 program under the ETN project "Enabling Excellence" Grant Agreement 642742. 


\section{REFERENCES}

1. Wiegers, G. A., Misfit Layer Compounds: Structures and Physical Properties. Prog. Solid St. Chem. 1996, 24, 1-139.

2. Sugiura, K.; Ohta, H.; Nomura, K.; Hirano, M.; Hosono, H.; Koumoto, K., High Electrical Conductivity of Layered Cobalt Oxide $\mathrm{Ca}_{3} \mathrm{Co}_{4} \mathrm{O}_{9}$ Epitaxial Films Grown by Topotactic Ion-Exchange Method. Appl. Phys. Lett. 2006, 89, 032111.

3. Shikano, M.; Funahashi, R., Electrical and Thermal Properties of Single-Crystalline $\left(\mathrm{Ca}_{2} \mathrm{CoO}_{3}\right)_{0.7} \mathrm{CoO}_{2}$ with a $\mathrm{Ca}_{3} \mathrm{Co}_{4} \mathrm{O}_{9}$ Structure. Appl. Phys. Lett. 2003, 82, 1851-1853.

4. Merrill, D.; Moore, D.; Bauers, S.; Falmbigl, M.; Johnson, D. C., Misfit Layer Compounds and Ferecrystals: Model Systems for Thermoelectric Nanocomposites. Materials 2015, 8, 2000-2029.

5. Takeuchi, T.; Kondo, T.; Takami, T.; Takahashi, H.; Ikuta, H.; Mizutani, U.; Soda, K.; Funahashi, R.; Shikano, M.; Mikami, M.; Tsuda, S.; Yokoya, T.; Shin, S.; Muro, T., Contribution of Electronic Structure to the Large Thermoelectric Power in Layered Cobalt Oxides. Phys. Rev. B 2004, 69, 125410.

6. Smaalen, S. V., A Superspace Group Description of the Misfit Layer Structure of $(\mathrm{SnS})_{1.17}\left(\mathrm{NbS}_{2}\right)$. J. Phys.: Condens. Mater 1989, 1, 2791-2800.

7. Banik, A.; Vishal, B.; Perumal, S.; Datta, R.; Biswas, K. Energy Environ. Sci. 2016, 9, 2011-2019.

8. Chatterjee, A.; Biswas, K., Solution-Based Synthesis of Layered Intergrowth Compounds of the Homologous $\mathrm{Pb}_{m} \mathrm{Bi}_{2} n \mathrm{Te}_{3} n_{+} m$ Series as Nanosheets. Angew. Chem. Inter. Ed. 2015, 54, 5623-5627.

9. Lin, Q.; Smeller, M.; Heideman, C. L.; Zschack, P.; Koyano, M.; Anderson, M. D.; Kykyneshi, R.; Keszler, D. A.; Anderson, I. M.; Johnson, D. C., Rational Synthesis 
and Characterization of a New Family of Low Thermal Conductivity Misfit Layer Compounds $\left[(\mathrm{PbSe})_{0.99}\right]_{\mathrm{m}}\left(\mathrm{WSe}_{2}\right)_{\mathrm{n}}$. Chem. Mater. 2010, 22, 1002-1009.

10. Ohta, H.; Sugiura, K.; Koumoto, K., Recent Progress in Oxide Thermoelectric Materials: p-Type $\mathrm{Ca}_{3} \mathrm{Co}_{4} \mathrm{O}_{9}$ and n-Type $\mathrm{SrTiO}_{3}{ }^{-}$. Inorg. Chem. 2008, 47, 8429-8436.

11. Masset, A. C.; Michel, C.; Maignan, A.; Hervieu, M.; Toulemonde, O.; Studer, F.; Raveau, B.; Hejtmanek, J., Misfit-Layered Cobaltite with an Anisotropic Giant Magnetoresistance: $\mathrm{Ca}_{3} \mathrm{Co}_{4} \mathrm{O}_{9}$. Phys. Rev. B 2000, 62, 166-175.

12. Pelloquin, D.; Hébert, S.; Maignan, A.; Raveau, B., A New Thermoelectric Misfit Cobaltite: $\left[\mathrm{Sr}_{2} \mathrm{CoO}_{3}\right]\left[\mathrm{CoO}_{2}\right]_{1.8}$. Solid State Sci. 2004, 6, 167-172.

13. Sakai, A.; Kanno, T.; Yotsuhashi, S.; Okada, S.; Adachi, H., Preparation of Metastable $\mathrm{Sr}_{3} \mathrm{Co}_{4} \mathrm{O}_{9}$ Epitaxial Thin Films with Controlled Orientation and Their Anisotropic Thermoelectric Properties. J. Appl. Phys. 2006, 99, 093704.

14. Matsubara, I.; Funahashi, R.; Shikano, M.; Sasaki, K.; Enomoto, H., Cation Substituted $\left(\mathrm{Ca}_{2} \mathrm{CoO}_{3}\right)_{x} \mathrm{CoO}_{2}$ Films and Their Thermoelectric Properties. Appl. Phy. Lett 2002, 80, 4729-4731.

15. Hicks, L. D.; Dresselhaus, M. S., Thermoelectric Figure of Merit of a OneDimensional Conductor. Phys. Rev. B 1993, 47, 16631-16634.

16. Radovsky, G.; Popovitz-Biro, R.; Staiger, M.; Gartsman, K.; Thomsen, C.; Lorenz, T.; Seifert, G.; Tenne, R., Synthesis of Copious Amounts of $\mathrm{SnS}_{2}$ and $\mathrm{SnS}_{2} / \mathrm{SnS}$ Nanotubes with Ordered Superstructures. Angew. Chem. Inter. Ed. 2011, 50, 1231612320.

17. Panchakarla, L. S.; Radovsky, G.; Houben, L.; Popovitz-Biro, R.; Dunin-Borkowski, R. E.; Tenne, R., Nanotubes from Misfit Layered Compounds: A New Family of Materials with Low Dimensionality. J. Phys. Chem. Lett. 2014, 5, 3724-3736. 
18. Radovsky, G.; Popovitz-Biro, R.; Stroppa, D. G.; Houben, L.; Tenne, R., Nanotubes from Chalcogenide Misfit Compounds: $\mathrm{Sn}-\mathrm{S}$ and $\mathrm{Nb}-\mathrm{Pb}-\mathrm{S}$. Acc. Chem. Res 2014, $47,406-416$.

19. Radovsky, G.; Popovitz-Biro, R.; Tenne, R., Nanotubes from the Misfit Layered Compounds MS-TaS 2 , Where $\mathrm{M}=\mathrm{Pb}, \mathrm{Sn}, \mathrm{Sb}$, or Bi: Synthesis and Study of Their Structure. Chem. Mater. 2014, 26, 3757-3770.

20. Radovsky, G.; Popovitz-Biro, R.; Lorenz, T.; Joswig, J.-O.; Seifert, G.; Houben, L.; Dunin-Borkowski, R. E.; Tenne, R., Tubular Structures from the $\mathrm{LnS}_{-\mathrm{TaS}}(\mathrm{Ln}=\mathrm{La}$, Ce, Nd, Ho, Er) and LaSe-TaSe 2 Misfit Layered Compounds. J. Mater. Chem. C 2016, 4, 89-98.

21. Panchakarla, L. S.; Lajaunie, L.; Tenne, R.; Arenal, R., Atomic Structural Studies on Thin Single-Crystalline Misfit-Layered Nanotubes of TbS-CrS 2 . J. Phys. Chem. C 2016, 120, 15600-15607.

22. Panchakarla, L. S.; Lajaunie, L.; Ramasubramaniam, A.; Arenal, R.; Tenne, R., Nanotubes from Oxide-Based Misfit Family: The Case of Calcium Cobalt Oxide. ACS Nano 2016, 10, 6248-6256.

23. Barthel, J., "Dr. Probe-STEM simulation software" 2016 available from: http://www.er-c.org/barthel/drprobe/index.html.

24. Peña, F. d. 1.; Ostasevicius, T.; Fauske, V. T.; Burdet, P.; Jokubauskas, P.; Sarahan, M.; Johnstone, D.; Nord, M.; Taillon, J.; Caron, J.; MacArthur, K. E.; Eljarrat, A.; Mazzucco, S.; Furnival, T.; Prestat, E.; Walls, M.; Donval, G.; Martineau, B.; Zagonel, L. F.; Garmannslund, A.; Aarholt, T.; Gohlke, C.; iygr. hyperspy: HyperSpy 1.1, 2016. doi:10.5281/zenodo.59293. 
25. Arenal, R.; de la Peña, F.; Stéphan, O.; Walls, M.; Tencé, M.; Loiseau, A.; Colliex, C., Extending the Analysis of Eels Spectrum-Imaging Data, from Elemental to Bond Mapping in Complex Nanostructures. . Ultramicroscopy 2008, 109, 32-38.

26. Ewels, P.; Sikora, T.; Serin, V.; Ewels, C. P.; Lajaunie, L.; , “A Complete Overhaul of the Electron Energy-Loss Spectroscopy and X-Ray Absorption Spectroscopy Database: Eelsdb.Eu. . Microsc. Microanal. 2016, 22, 717-724.

27. Kresse, G.; Furthmüller, J., Efficiency of Ab-Initio Total Energy Calculations for Metals and Semiconductors Using a Plane-Wave Basis Set. Comput. Mater. Sci. 1996, $6,15-50$

28. Kresse, G.; Furthmüller, J., Efficient Iterative Schemes for Ab Initio Total-Energy C alculations Using a Plane-Wave Basis Set. Phys. Rev. B 1996, 54, 11169-11186.

29. Blöchl, P. E., Projector Augmented-Wave Method. Phys. Rev. B 1994, 50, $17953-$ 17979.

30. Kresse, G.; Joubert, D., From Ultrasoft Pseudopotentials to the Projector AugmentedWave Method. Phys. Rev. B 1999, 59, 1758-1775.

31. Perdew, J. P.; Burke, K.; Ernzerhof, M., Generalized Gradient Approximation Made Simple. Phys. Rev. Lett. 1996, 77, 3865-3868.

32. Dudarev, S. L.; Botton, G. A.; Savrasov, S. Y.; Humphreys, C. J.; Sutton, A. P., Electron-Energy-Loss Spectra and the Structural Stability of Nickel Oxide: An LSDA+U Study. Phys. Rev. B 1998, 57, 1505-1509.

33. Rébola, A.; Klie, R. F.; Zapol, P.; Öğüt, S., Phonon and Thermal Transport Properties of the Misfit-Layered Oxide Thermoelectric $\mathrm{Ca}_{3} \mathrm{Co}_{4} \mathrm{O}_{9}$ from First Principles. Appl. Phy. Lett 2014, 104, 251910. 
34. Baran, J. D.; Molinari, M.; Kulwongwit, N.; Azough, F.; Freer, R.; Kepaptsoglou, D.; Ramasse, Q. M.; Parker, S. C., Tuning Thermoelectric Properties of Misfit Layered Cobaltites by Chemically Induced Strain. J. Phys. Chem. C 2015, 119, 21818-21827.

35. Blöchl, P. E.; Jepsen, O.; Andersen, O. K., Improved Tetrahedron Method for Brillouin-Zone Integrations. Phys. Rev. B 1994, 49, 16223-16233.

36. Bader, R. F. W., A Quantum Theory of Molecular Structure and Its Applications. Chem. Rev. 1991, 91, 893-928.

37. Henkelman, G.; Arnaldsson, A.; Jónsson, H., A Fast and Robust Algorithm for Bader Decomposition of Charge Density. Comput. Mater. Sci. 2006, 36, 354-360.

38. Ylvisaker, E. R.; Pickett, W. E.; Koepernik, K., Anisotropy and Magnetism in the LSDA+U Method. Phys. Rev. B 2009, 79, 035103.

39. Meredig, B.; Thompson, A.; Hansen, H. A.; Wolverton, C.; van de Walle, A., Method for Locating Low-Energy Solutions within DFT+U. Phys. Rev. B 2010, 82, 195128.

40. Panchakarla, L. S.; Popovitz-Biro, R.; Houben, L.; Dunin-Borkowski, R. E.; Tenne, R., Lanthanide-Based Functional Misfit-Layered Nanotubes. Angew. Chem. Int. Ed. 2014, 53, 6920-6924.

41. Rébola, A.; Klie, R.; Zapol, P.; Öğüt, S., First-Principles Study of the Atomic and Electronic Structures of Misfit-Layered Calcium Cobaltite $\left(\mathrm{Ca}_{2} \mathrm{CoO}_{3}\right)\left(\mathrm{CoO}_{2}\right)_{1.62}$ Using Rational Approximants. Phys. Rev. B 2012, 85, 155132.

42. Gross, K.; Barragán, J. J. P.; Sangiao, S.; Teresa, J. M. D.; Lajaunie, L.; Arenal, R.; Calderón, H. A.; Prieto, P., Electrical Conductivity of Oxidized-Graphenic Nanoplatelets Obtained from Bamboo: Effect of the Oxygen Content. Nanotechnology 2016, 27, 365708.

43. Lajaunie, L.; Pardanaud, C.; Martin, C.; Puech, P.; Hu, C.; Biggs, M. J.; Arenal, R., Advanced Spectroscopic Analyses on A:C-H Materials: Revisiting the Eels 
Characterization and Its Coupling with Multi-Wavelength Raman Spectroscopy. Carbon 2017, 112, 149-161.

44. Arenal, R.; March, K.; Ewels, C. P.; Rocquefelte, X.; Kociak, M.; Loiseau, A.; Stéphan, O., Atomic Configuration of Nitrogen-Doped Single-Walled Carbon Nanotubes. Nano Lett. 2014, 14, 5509-5516.

45. Arenal, R.; Stephan, O., In "Advanced Transmission Electron Microscopy: Applications to Nanomaterials”, Deepak, F. L.; Mayoral, A.; Arenal, R., Eds. Springer 2015.

46. Schmidt, O. G.; Eberl, K., Nanotechnology: Thin Solid Films Roll up into Nanotubes. Nature 2001, 410, 168-168.

47. Zhang, S.; Peng, L. M.; Chen, Q.; Du, G. H.; Dawson, G.; Zhou, W. Z., Formation Mechanism of $\mathrm{H}_{2} \mathrm{Ti}_{3} \mathrm{O}_{7}$ Nanotubes. Phys. Rev. Lett. 2003, 91, 256103.

48. Du, G.; Chen, Q.; Yu, Y.; Zhang, S.; Zhou, W.; Peng, L.-M., Synthesis, Modification and Characterization of $\mathrm{K}_{4} \mathrm{Nb}_{6} \mathrm{O}_{17}$-Type Nanotubes. J. Mater. Chem. 2004, 14, $1437-$ 1442. 